\title{
Primary adrenal insufficiency in adult population: a Portuguese Multicentre Study by the Adrenal Tumours Study Group
}

\author{
Lia Ferreira', João Silva², Susana Garrido ${ }^{3}$ Carlos Bello4, Diana Oliveira5, \\ Hélder Simões ${ }^{6}$, Isabel Paiva ${ }^{5}$, Joana Guimarães7, Marta Ferreira ${ }^{8}$, Teresa Pereira ${ }^{8}$, \\ Rita Bettencourt-Silva ${ }^{9}$, Ana Filipa Martins ${ }^{10}$, Tiago Silva ${ }^{11}$, Vera Fernandes ${ }^{12}$, \\ Maria LopesPereira ${ }^{12}$ and Adrenal Tumors Study Group of the Portuguese Society \\ of Endocrinology
}

${ }^{1}$ Department of Endocrinology, Centro Hospitalar do Porto, Porto, Portugal ${ }^{2}$ Department of Endocrinology, Hospital das Forças Armadas, Lisboa, Portugal ${ }^{3}$ Department of Endocrinology, Centro Hospitalar Tâmega e Sousa, Porto, Portugal

${ }^{4}$ Department of Endocrinology, Centro Hospitalar Lisboa Ocidental, Lisboa, Portugal

${ }^{5}$ Department of Endocrinology, Centro Hospitalar e Universitário de Coimbra, Coimbra, Portugal

${ }^{6}$ Department of Endocrinology, Instituto Português de Oncologia de Lisboa Francisco Gentil, Lisboa, Portugal ${ }^{7}$ Department of Endocrinology, Centro Hospitalar do Baixo Vouga, Aveiro, Portugal

${ }^{8}$ Department of Endocrinology, Centro Hospitalar de Leiria, Leiria, Portugal

${ }^{9}$ Department of Endocrinology, Centro Hospitalar de São João, Porto, Portugal

${ }^{10}$ Department of Endocrinology, Centro Hospitalar Lisboa Norte, Lisboa, Portugal

${ }^{11}$ Department of Endocrinology, Hospital Garcia da Orta, Lisboa, Portugal

${ }^{12}$ Department of Endocrinology, Hospital de Braga, Braga, Portugal

Correspondence should be addressed to L Ferreira Email

liaferreira00@gmail.com

\begin{abstract}
Introduction: Primary adrenal insufficiency (PAI) is a rare but severe and potentially life-threatening condition. No previous studies have characterized Portuguese patients with PAI.

Aims: To characterize the clinical presentation, diagnostic workup, treatment and follow-up of Portuguese patients with confirmed PAI.

Methods: This multicentre retrospective study examined PAI patients in 12 Portuguese hospitals.

Results: We investigated 278 patients with PAI (55.8\% were females), with a mean age of $33.6 \pm 19.3$ years at diagnosis. The most frequent presenting clinical features were asthenia $(60.1 \%)$, mucocutaneous hyperpigmentation $(55.0 \%)$ and weight loss $(43.2 \%)$; $29.1 \%$ of the patients presented with adrenal crisis. Diagnosis was established by high plasma ACTH and low serum cortisol in most patients $(43.9 \%)$. The most common aetiology of PAI was autoimmune adrenalitis (61.0\%). There were 38 idiopathic cases. Autoimmune comorbidities were found in $70 \%$ of the patients, the most frequent being autoimmune thyroiditis $(60.7 \%)$ and type 1 diabetes mellitus (17.3\%). Seventynine percent were treated with hydrocortisone (mean dose $26.3 \pm 8.3 \mathrm{mg} /$ day) mostly in three $(57.5 \%)$ or two $(37.4 \%)$ daily doses. The remaining patients were treated with prednisolone $(10.1 \%)$, dexamethasone $(6.2 \%)$ and methylprednisolone $(0.7 \%) ; 66.2 \%$ were also on fludrocortisone (median dose of $100 \mu \mathrm{g} /$ day). Since diagnosis, $33.5 \%$ of patients were hospitalized for disease decompensation. In the last appointment,
\end{abstract}

http://www.endocrineconnections.org DOI: 10.1530/EC-17-0295 (c) 2018 The authors Published by Bioscientifica Ltd

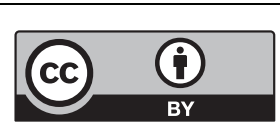

This work is licensed under a Creative Commons Attribution 4.0 International License. 
$17.2 \%$ of patients had complaints ( $7.6 \%$ asthenia and $6.5 \%$ depression) and $9.7 \%$ had electrolyte disturbances.

Conclusion: This is the first multicentre Portuguese study regarding PAI. The results emphasize the need for standardization in diagnostic tests and etiological investigation and provide a framework for improving treatment.

\section{Introduction}

Addison disease (AD) or primary adrenal insufficiency (PAI) is a life-threatening disease that results from bilateral destruction or dysfunction of the adrenal cortex (1). PAI is a rare disease with a reported prevalence of approximately 100 per million inhabitants in European countries. The incidence has been estimated at 4-6 cases per million per year but seems to be increasing $(2,3,4,5,6,7,8)$.

Tuberculosis has historically been the predominant cause of $\operatorname{AD}(9,10,11,12)$, but autoimmune adrenalitis is now the most prevalent aetiology (80-90\%) in industrialized countries $(1,4,5,7,13)$. Other causes include infectious, genetic, metastatic, haemorrhagic and infiltrative disorders, as well as surgery or drugs, but these cases are rare in adult patients.

Autoimmune adrenalitis is frequently associated with other organ-specific autoimmune disorders and type 1 or type 2 autoimmune polyendocrine syndrome (APS- 1 and APS-2). APS- 1 is a very rare monogenic disorder caused by mutations in the autoimmune regulator (AIRE) gene and is characterized by the presence of two of the three main components: AD, chronic mucocutaneous candidiasis and hypoparathyroidism. The more common APS-2 is characterized by two or more concurrent autoimmune endocrinopathies, such as $\mathrm{AD}$, autoimmune hypo- or hyperthyroidism and type 1 diabetes mellitus (DM) (14). Isolated PAI and APS- 2 share the same pattern of complex inheritance (7).

To date, no data have been available about the epidemiology, clinical features and management of Portuguese patients with PAI. The main objective of this study is to characterize the clinical presentation, diagnostic workup, treatment and follow-up of such patients. Other objectives of this study are to explore the treatment modalities in this group and identify the most prevalent concomitant diseases.

\section{Methods}

This observational, multicentre, retrospective study investigated patients older than 18 years with a diagnosis of PAI followed by endocrinology in 12 national hospitals (four in Northern Portugal, three in Central Portugal, and five in Southern Portugal). Hospitals in the Adrenal Tumours Study Group (GET-SR) of the Portuguese Society of Endocrinology were invited to participate in the study. Patient selection and data collection occurred between September and November 2016. All patient clinical data were anonymized and analysed by an independent reviewer. Consent has been obtained from each patient after full explanation of the purpose and nature of all procedures used. Ethical approval was granted by the Ethics Committee of Centro Hospitalar de São João.

The diagnosis of PAI was verified by review of medical records by 15 endocrinologists and endocrinology residents from the 12 Portuguese centres. AD was diagnosed based on one of the following criteria: (1) a plasma adrenocorticotropic hormone (ACTH) concentration exceeding $66 \mathrm{pmol} / \mathrm{L}$ in combination with a low serum cortisol ( $<5 \mu \mathrm{g} / \mathrm{dL})$; (2) an abnormal standard dose ACTH stimulation test (peak plasma cortisol $<18 \mu \mathrm{g} / \mathrm{dL}$ ); (3) characteristic clinical signs and symptoms such as hyperpigmentation, salt craving, typical electrolyte disturbances and chronic treatment with glucocorticoids and fludrocortisone in patients who were diagnosed decades ago. The diagnosis of autoimmune AD was based on positive autoantibodies toward 21-hydroxylase or associated autoimmune diseases.

Cases with no known cause were classified as idiopathic. Patients were excluded if their adrenal insufficiency was deemed to be secondary to adrenalectomy, pituitary surgery or prolonged use of glucocorticoids. Patients who died since diagnosis were also excluded.

We studied patient demographic and clinical data, particularly regarding diagnosis, aetiology, concomitant autoimmune disorders, family history and replacement regimens, such as the type, daily dosage and dose frequency of glucocorticoids, as well as the use of mineralocorticoids. We assessed the occurrence of hospitalization due to adrenal crisis through the review of all hospital medical records since the diagnosis. Adrenal crisis (AC) was defined as an acute impairment of general

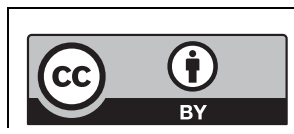

This work is licensed under a Creative Commons Attribution 4.0 International License. 
health requiring hospital admission and administration of intravenous saline and glucocorticoids in patients with AD. Furthermore, symptoms and electrolyte disturbances at the last appointment were evaluated.

A comparative analysis was performed to investigate the type of glucocorticoid replacement and aetiology, mean daily hydrocortisone equivalent dose, mean daily fludrocortisone dose, occurrence of $\mathrm{AC}$ and the presence of symptoms or electrolyte disturbances. Data were initially collected in an Excel 2011 database, and statistical analysis was performed with SPSS Statistics, V.22. Data are presented as proportions, means (s.D.) or medians (range) for variables that did not conform to a normal distribution. The crude incidence rates of hospitalization due to AC were estimated as the number of hospitalization cases divided by the total follow-up time and were reported as number of cases per 100 patient-years. For independent samples, two-way comparisons for proportions were performed using a chi-square test $\left(\chi^{2}\right)$ for categorical variables and a $t$-test or Mann-Whitney $U$ test for continuous variables. Statistical significance was taken as two-tailed at the level of 0.05 . All phases of preparation for the study were in line with the ethical and deontological principles regarding data collection and statistical analysis.

\section{Results}

The study included 278 adult patients diagnosed with AD between 1950 and 2016, of which 56\% were female. The mean age at diagnosis was $33.6 \pm 19.3$ years.

\section{Clinical presentation}

At the time of the diagnosis, the most frequently reported symptoms and signs were asthenia (60.1\%), mucocutaneous hyperpigmentation (55.0\%), weight loss $(43.2 \%)$, hypotension (42.8\%) and hypoglycaemia (8.6\%). Hyponatraemia was documented in 36.3\% of cases, while hyperkalaemia occurred in $25.9 \%$. AC was diagnosed in $29.1 \%$ of the patients. The median lag time between onset of symptoms and confirmed diagnosis was 3 (0-36) months.

\section{Diagnosis workup}

The diagnoses were established by high ACTH and low serum cortisol in 122 (43.9\%) patients; by an abnormal standard dose ACTH stimulation test (peak plasma cortisol $<18 \mu \mathrm{g} / \mathrm{dL})$ in $39(14.0 \%)$ patients and by characteristic clinical symptoms/signs and chronic treatment with glucocorticoids and fludrocortisone in 48 (17.3\%) patients who were diagnosed decades ago. These data were missing for $69(24.8 \%)$ patients.

Data regarding etiological investigation were available in 246 patients. The most common causes were autoimmune adrenalitis (61.0\%), genetic-related $\mathrm{AD}(14.2 \%)$ and infectious adrenalitis (7.3\%). Thirtyeight cases (15.4\%) were considered idiopathic. We also documented three cases secondary to bilateral adrenal haemorrhage and two cases of adrenal metastatic infiltration. Figure 1 summarizes the frequency of different forms of AD diagnosed from 1950 to 2016.

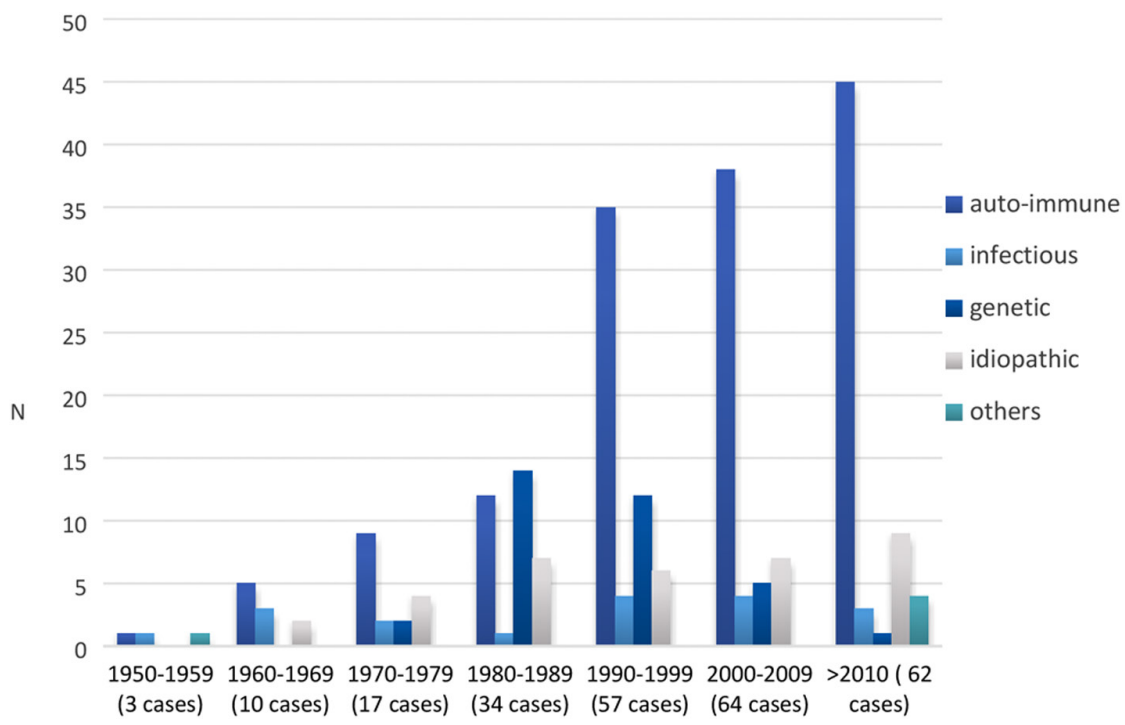

Figure 1

Frequency of $A D$ cases according to date of diagnosis and aetiology. (c) 2017 The authors Published by Bioscientifica Ltd

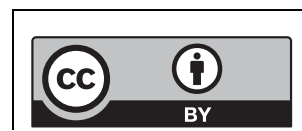

This work is licensed under a Creative Commons Attribution 4.0 International License. http://www.endocrineconnections.org
DOI: 10.1530/EC-17-0295 


\section{Patients with autoimmune AD}

Among 150 patients with autoimmune AD, 65.3\% were female and the mean age at diagnosis was $34.9 \pm 15.9$ years. The mean age of diagnosis was higher for females, $37.9 \pm 15.3$ years than for males, $29.2 \pm 15.5$ years $(P<0.001)$

Ninety-threepercent of the patients had autoantibodies directed against 21-hydroxylase. Computed tomography (CT) scans of the adrenal glands were performed in 50 patients, among which adrenal morphology was described as normal in 37 cases, while 13 patients presented reduced size or volume.

\section{Associated endocrine and autoimmune disorders}

Isolated autoimmune $\mathrm{AD}$ occurred in $30 \%$ of the patients, whereas $70 \%$ were diagnosed with one or more associated autoimmune endocrinopathies. The most common of these were autoimmune thyroiditis (60.7\%), type 1 diabetes mellitus (17.3\%) and pernicious anaemia $(6.7 \%)$, with $103(68.7 \%)$ of the patients meeting the criteria for APS-2. We also found two patients with associated chronic mucocutaneous candidiasis and meeting the criteria for APS-1. Other recorded comorbidities are presented in Fig. 2.

\section{Patients with genetic forms of AD}

Congenital adrenal hyperplasia (CAH) resulting from 21-hydroxylase deficiency occurred in 27 patients (55.6\% female), with a median age at onset of 3 (range, $0-30)$ years. The diagnosis of $\mathrm{CAH}$ was based on the molecular analysis of CYP21A2 gene. Five patients had $\mathrm{X}$-linked adrenoleukodystrophy (ALD), with a median age at diagnosis of 25 (range, 11-28) years. Three patients had $\mathrm{X}$-linked congenital adrenal hypoplasia with a mutation of DAX1, who were all diagnosed within the first year of life.

\section{Patients with post-infectious AD}

Out of the 18 cases (50\% female) of infectious adrenalitis, 17 resulted from tuberculosis and one resulted from histoplasmosis. The median age at diagnosis was 50 (range, 18-69) years. Ten patients had records of radiological studies, of which seven showed an increase in adrenal volume and three had adrenal glands with normal morphology.

\section{Idiopathic AD}

In the 38 cases considered idiopathic, the median age at diagnosis was 41 (range, 5-78) years. Only two of these patients had records of anti-adrenal antibodies (negative), and 18 patients had radiological imaging of the adrenal glands (the adrenals were reduced in size/volume with calcifications in five patients and normal in 13 patients).

\section{Treatment and follow-up}

All patients received glucocorticoid replacement therapy, $79.1 \%$ t were treated with hydrocortisone, $10.1 \%$ with prednisolone, $6.1 \%$ with dexamethasone and $0.7 \%$ methylprednisolone (missing data $=11$ ). The mean daily dose for patients with hydrocortisone treatment was $26.3 \pm 8.3 \mathrm{mg} /$ day (missing data $=1$ ), which was divided into one $(3.5 \%)$, two $(37.4 \%)$, three $(57.5 \%)$ or four $(0.5 \%)$ daily doses (missing data $=3)$. Other glucocorticoid replacement doses were recalculated as the hydrocortisone equivalent dose (Table 1). Patients receiving hydrocortisone had a significantly higher mean daily hydrocortisone equivalent dose than patients receiving prednisolone (mean difference of $4.7 \pm 1.6 \mathrm{mg} /$ day; $P<0.05$ ) and dexamethasone (mean difference of $15.2 \pm 2.0 \mathrm{mg} /$ day; $\quad P<0.001)$. Replacement with dexamethasone was significantly more frequent among

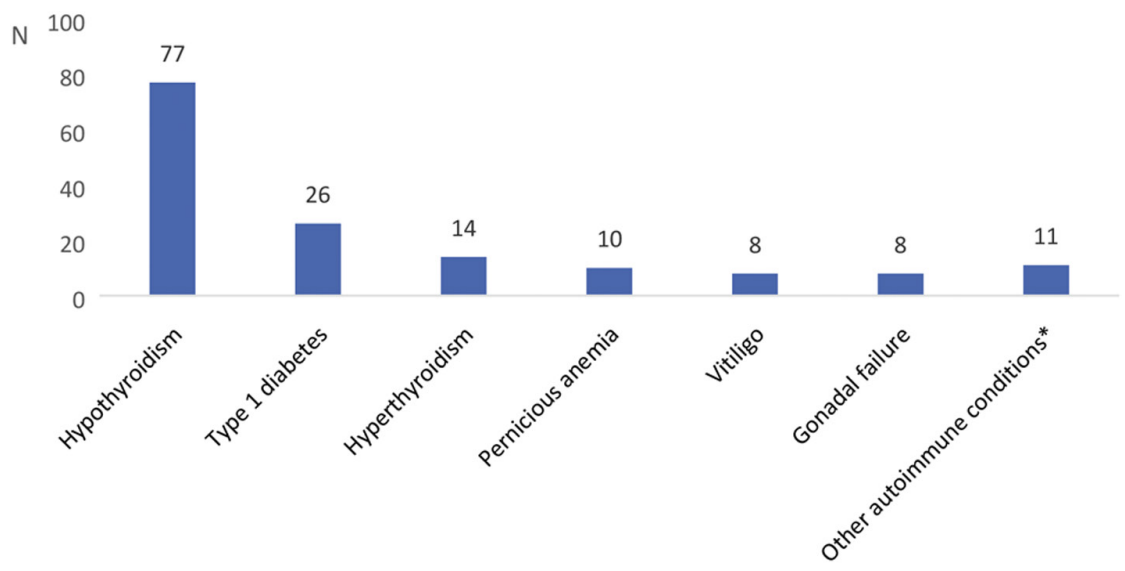

Figure 2

Frequency of concomitant endocrine and autoimmune diseases in patients with autoimmune AD. *other: chronic mucocutaneous candidiasis, hypoparathyroidism, alopecia.

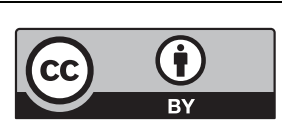


Table 1 Glucocorticoid and mineralocorticoid replacement.

\begin{tabular}{|c|c|c|}
\hline $\begin{array}{l}\text { Glucocorticoid therapy } \\
(N=267)\end{array}$ & $\%$ & $\begin{array}{l}\text { Mean daily hydrocortisone } \\
\text { equivalent dose (mg) }\end{array}$ \\
\hline Hydrocortisone & 79.1 & $26.3 \pm 8.3$ \\
\hline Prednisolone & 10.1 & $21.6 \pm 7.4$ \\
\hline Dexamethasone & 6.1 & $11.1 \pm 7.4$ \\
\hline Methylprednisolone & 0.7 & 20 \\
\hline Total & 100 & $24.8 \pm 8.9$ \\
\hline
\end{tabular}

\begin{tabular}{l}
$\frac{1}{3.7}$ \\
100 \\
100 \\
100 \\
15.8 \\
\hline
\end{tabular}

\begin{tabular}{|c|c|c|}
\hline \multicolumn{3}{|c|}{ Doses/day (\%) } \\
\hline 2 & 3 & 4 \\
\hline 37.4 & 57.5 & 0.5 \\
\hline - & - & - \\
\hline - & - & - \\
\hline- & - & - \\
\hline 33.1 & 45.7 & 0.7 \\
\hline
\end{tabular}

\begin{tabular}{c}
$\begin{array}{c}\text { Mineralocorticoid } \\
\text { therapy (\%) }\end{array}$ \\
\hline 68.9 \\
88.9 \\
52.9 \\
0 \\
66.5
\end{tabular}

\begin{tabular}{c}
$\begin{array}{c}\text { Median daily dose of } \\
\text { fludrocortisone }(\mu \mathrm{g})\end{array}$ \\
\hline 100 (range $25-200)$ \\
100 (range $50-200)$ \\
100 (range $50-150)$ \\
- \\
100 (range $25-200)$
\end{tabular}

patients with $\mathrm{CAH}(82.4 \%$ vs $17.6 \% ; P<0.001)$. There were no differences between the other types of glucocorticoid replacement and aetiology.

Mineralocorticoid replacement was utilized by $66.5 \%$ of the patients, and the median fludrocortisone dose was 100 (range, 25-200) $\mu \mathrm{g} /$ day. The two patients under methylprednisolone replacement did not receive mineralocorticoid. The prevalence of fludrocortisone replacement was higher in patients with prednisolone (88.9\%) than in patients with hydrocortisone $(68.9 \%$; $P=0.021)$ or dexamethasone $(52.9 \% ; P=0.01)$, but there were no differences regarding daily fludrocortisone dose $(P=0.46)$. The mean hydrocortisone equivalent dose was not significantly different in patients with or without mineralocorticoid replacement $(24.0 \pm 8.1 \mathrm{mg} /$ day vs $25.1 \pm 9.3 \mathrm{mg} /$ day; $P=0.35$ ) .

Since the diagnosis, $33.5 \%$ of patients had been hospitalized due to AC. The overall incidence of AC was 4.36 (95\% CI 3.98-4.74) per 100 patient-years. The incidence rate of hospital admission was higher in the group receiving hydrocortisone (4.94, 95\% CI 4.51-5.34) than in the group receiving prednisolone $(2.78,95 \%$ CI $1.99-3.56)$ per 100 patient-years $(P=0.001)$. There were no differences between dose of glucocorticoid, mineralocorticoid replacement or aetiology and the incidence of hospitalizations.

At the last appointment, $17.2 \%$ of the patients had complaints (missing data $=31$ ) with most common being asthenia (7.6\%) and depression (6.5\%), while 9.7\% presented electrolyte disturbances (missing data $=17$ ). No association was found between complaints and the type of glucocorticoid replacement, mineralocorticoid therapy, the presence of symptoms or electrolyte disturbances.

\section{Discussion}

We reviewed 278 adult patients with $\mathrm{AD}$ followed by endocrinology in 12 Portuguese hospitals. To date, this is the only Portuguese cohort of patients with PAI. Several patients may be followed in other centres or by other

specialties, so we were not able to estimate the prevalence of this disease in Portugal. However, considering the dimension and the good distribution of patients across the country, we assume that this cohort is representative of the Portuguese population with AD.

Several recent studies have suggested an increasing incidence of the disease in the last decades $(2,3,4,8$, 15). In our study, it was not possible to determine the incidence of $\mathrm{AD}$ over time, however, in agreement with recent data, we found an increasing relative proportion of autoimmune $\mathrm{AD}$ cases and a decrease in infectious etiologies over the last decades $(1,4,13)$. These findings are consistent with the widespread increase in autoimmune diseases and the decline in the prevalence of tuberculosis in industrialized countries (3). In line with the results from Lauretta and coworkers, the majority of patients in this cohort were female (5). This difference was more evident in patients with autoimmune $\mathrm{AD}$ (64.3\% vs $35.7 \% ; P=0.017)$.

In our cohort, only $14 \%$ of patients had records of a corticotropin test. Current guidelines by the Endocrine Society suggest that only if a corticotropin test is not feasible should the combination of low plasma cortisol and ACTH $>2$ times the upper reference limit be used as a preliminary test for suggesting adrenal insufficiency (16). However, in our study, most cases were diagnosed several decades ago when the availability of corticotropin was limited.

The most common aetiology was autoimmune AD, and $68 \%$ of this subset of patients had other autoimmune endocrinopathy. The most frequent concomitant diseases were hypothyroidism, DM, hyperthyroidism and pernicious anaemia, which is in concordance with studies from Norway (7), Italy (1), the United Kingdom (UK) (17), Sweden (18) and Poland (19).

We found 35 patients with genetic forms of adrenal insufficiency, and $\mathrm{CAH}$ was the most frequent. CAH is the most common cause of adrenal insufficiency in infancy (20). Considering the exclusion of paediatric patients and the possible loss of continuity of endocrine specialist care from the paediatric to adult environments,

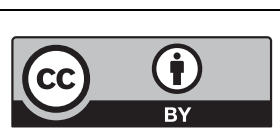

This work is licensed under a Creative Commons Attribution 4.0 International License. 
we assume that the real number of patients with $\mathrm{CAH}$ and probably other genetic forms of AD is underestimated in our study.

The frequency of idiopathic cases was somewhat higher than that reported in other studies $(13,21)$. Only two patients had records of anti-adrenal antibodies, and 18 had radiological studies of the adrenals. Considering the radiological findings in some of the patients defined as idiopathic, these may correspond to a fraction of underdiagnosed cases of autoimmune or tuberculosis AD. Current guidelines recommend that the aetiology of PAI be determined in all patients. According to the patients' clinical pictures and family histories, etiologies can be screened using 21-hydroxylase antibodies and the 17-hydroxyprogesterone serum level at baseline. If antibodies are negative, a CT scan of the adrenals may reveal evidence of adrenal infiltrative processes or metastases, and male patients should be tested for adrenoleukodystrophy with plasma levels of very-longchain fatty acids $(16,22)$. The high number of idiopathic cases in this study likely reflects the incomplete etiological study of some of these patients.

Current treatment recommendations suggest using short-acting glucocorticoids, hydrocortisone (15-25 mg) or cortisone acetate $(20-35 \mathrm{mg}$ ) in two or three divided oral doses per day to avoid overtreatment and enable a diurnal physiological pattern (22). Our study revealed that Portuguese patients primarily use short-acting glucocorticoids, which are mostly divided into three daily doses. We found similar data from other European countries in the literature $(1,7,18)$. The mean daily equivalent hydrocortisone dose found in this study ( $26.3 \mathrm{mg} /$ day) was slightly higher than the recommended dose (16). Lower doses have been reported in studies in the United Kingdom (24.0 mg/day) and Italy (25.2 mg/day) $(17,21)$, but the use of higher doses was found in a Norwegian study (32.4mg/day) (7). Furthermore, we found that patients receiving long-acting glucocorticoids used a significantly lower mean hydrocortisone equivalent dose than patients on conventional hydrocortisone replacement. However, these preparations are associated with a non-physiological plasma cortisol profile and may result in symptoms of over- or under-substitution, despite optimal dose steroid replacement.

Mineralocorticoid replacement therapy with fludrocortisone is recommended in all patients with PAI (16). The mineralocorticoid replacement rate found in this study $(66.5 \%)$ was somewhat lower than that reported by other studies. In Swedish and UK cohorts, 89\% and 100\% of patients were on fludrocortisone, respectively $(17,18)$.
The incidence rate of hospitalizations due to $\mathrm{AC}$ found in this population was lower than that reported in Dutch (5.2/100 person-year) and German (6.3/100 patient-years) patients $(23,24)$. However, the exclusion of deaths from the assessment is likely to lead to an underestimation of the real incidence of AC in this study, as there is a mortality rate associated with $\mathrm{AC}(25,26)$ and moreover some of these events may have occurred outside hospital. The higher incidence of AC found in patients receiving hydrocortisone may be related with the likelihood that patients on short-acting glucocorticoid replacement therapy have periods of relatively profound hypocortisolaemia that may predispose patients to an AC (27). This finding also emphasizes the importance of patient education concerning glucocorticoid adjustments in stressful events and AC prevention strategies.

On the last appointment, $17 \%$ of our patients had complaints, and $10 \%$ had electrolyte disturbances. Unfortunately, it was not possible to evaluate in this study the morbidity and mortality associated with $\mathrm{AD}$. There is growing evidence that current replacement regimens are associated with a significant reduction in health status and working ability $(28,29)$. Moreover, premature death and increased mortality have been demonstrated among $\mathrm{AD}$ patients (26). These findings are thought to be due to the non-physiological nature of conventional replacement therapy (30). Delayed-release hydrocortisone preparations have been introduced with the aim of better mimicking the endogenous circadian cortisol rhythm, which have been shown to improve quality of life in patients with $\mathrm{AD}$ (31). However, these preparations are still not available in Portugal.

One of the strengths of this study is the inclusion of patients from most tertiary centres in the northern, central and southern regions of Portugal. It is also the first national cohort of patients with $\mathrm{AD}$, and it was possible to characterize the clinical presentation, diagnosis, treatment and follow-up of the disease.

The main limitations of this study stem from its retrospective observational nature in which data were collected from medical records by several investigators. We cannot draw any conclusions about the real incidence of the disease in our country, as this cohort just includes adult patients followed on endocrinology department. Furthermore, as aforementioned, the exclusion of deaths probably leads to an underestimation of the disease and incidence of AC.

In conclusion, autoimmune $\mathrm{AD}$ is the most frequent aetiology in this population, but there is still a high prevalence of cases considered idiopathic.

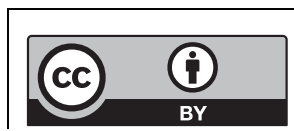

This work is licensed under a Creative Commons Attribution 4.0 International License. 
This study emphasizes the need for standardization in diagnostic tests, etiological investigation and the investigation of associated autoimmune comorbidities. It is also important to advocate the treatment of these patients according to current recommendations and to minimize symptoms associated with over- or undersubstitution of glucocorticoids and under replacement of mineralocorticoid.

\section{Declaration of interest}

The authors declare that there is no conflict of interest that could be perceived as prejudicing the impartiality of the research reported.

\section{Funding}

This research did not receive any specific grant from any funding agency in the public, commercial or not-for-profit sector.

\section{References}

1 Betterle C, Dal Pra C, Mantero F \& Zanchetta R. Autoimmune adrenal insufficiency and autoimmune polyendocrine syndromes: autoantibodies, autoantigens, and their applicability in diagnosis and disease prediction. Endocrine Reviews 200223 327-364. (doi:10.1210/ edrv.23.3.0466)

2 Olafsson AS \& Sigurjonsdottir HA. Increasing prevalence of Addison disease: results from a nationwide study. Endocrine Practice 201522 30-35. (doi:10.4158/EP15754.OR)

3 Meyer G, Neumann K, Badenhoop K \& Linder R. Increasing prevalence of Addison's disease in German females: health insurance data 2008-2012. European Journal of Endocrinology $2014170367-373$. (doi:10.1530/EJE-13-0756)

4 Løvås K \& Husebye ES. High prevalence and increasing incidence of Addison's disease in western Norway. Clinical Endocrinology 200256 787-791. (doi:10.1046/j.1365-2265.2002.t01-1-01552.x)

5 Laureti S, Vecchi L, Santeusanio F \& Falorni A. Is the prevalence of Addison's disease underestimated? Journal of Clinical Endocrinology and Metabolism 199984 1762. (doi:10.1210/jc.84.5.1762)

6 Kong MF \& Jeffcoate W. Eighty-six cases of Addison's disease. Clinical Endocrinology 199441 757-761. (doi:10.1111/j.1365-2265.1994. tb02790.x)

7 Erichsen MM, Løvås K, Skinningsrud B, Wolff AB, Undlien DE, Svartberg J, Fougner KJ, Berg TJ, Bollerslev J, Mella B, et al. Clinical, immunological, and genetic features of autoimmune primary adrenal insufficiency: observations from a Norwegian registry. Journal of Clinical Endocrinology and Metabolism 200994 4882-4890. (doi:10.1210/jc.2009-1368)

8 Willis AC \& Vince FP. The prevalence of Addison's disease in Coventry, UK. Postgraduate Medical Journal 199773 286-288. (doi:10.1136/pgmj.73.859.286)

9 Nerup J. Addison's disease-clinical studies. A report of 108 cases. Acta Endocrinologica 197476 127-141. (doi:10.1530/acta.0.0760127)

10 Mason AS, Meade T, Lee J \& Morris J. Epidemiological and clinical picture of Addison's disease. Lancet 1968292 744-747. (doi:10.1016/ S0140-6736(68)90948-3)

11 Guttman PH. Addison's disease. A statistical analysis of 566 cases and a study of the pathology. Archives of Pathology 193010 742-935.

12 Dunlop D. Eight-six cases of Addison's disease. British Medical Journal 19632 887. (doi:10.1136/bmj.2.5362.887)
13 Falorni A, Laureti S, De Bellis A, Zanchetta R, Tiberti C, Arnaldi G, Bini V, Beck-Peccoz P, Bizzarro A, Dotta F, et al. Italian Addison network study: update of diagnostic criteria for the etiological classification of primary adrenal insufficiency. Journal of Clinical Endocrinology and Metabolism 200489 1598-1604. (doi:10.1210/ jc.2003-030954)

14 Eisenbarth GS \& Gottlieb PA. Autoimmune polyendocrine syndromes. New England Journal of Medicine 2004350 2068-2079. (doi:10.1056/NEJMra030158)

15 Betterle C \& Morlin L. Autoimmune Addison's disease. Pediatric Adrenal Diseases 201120 161-172. (doi:10.1159/000321239)

16 Bornstein SR, Allolio B, Arlt W, Barthel A, Don-Wauchope A, Hammer GD, Husebye ES, Merke DP, Murad MH, Stratakis CA, et al. Diagnosis and treatment of primary adrenal insufficiency: an endocrine society clinical practice guideline. Journal of Clinical Endocrinology and Metabolism 2015101 364-389. (doi:10.1210/ jc.2015-1710)

17 Leelarathna L, Breen L, Powrie JK, Thomas SM, Guzder R, McGowan B \& Carroll PV. Co-morbidities, management and clinical outcome of auto-immune Addison's disease. Endocrine 201038 113-117. (doi:10.1007/s12020-010-9359-8)

18 Dalin F, Nordling Eriksson G, Dahlqvist P, Hallgren Å, Wahlberg J, Ekwall O, Söderberg S, Rönnelid J, Olcén P, Winqvist O, et al. Clinical and immunological characteristics of autoimmune Addison's disease: a nationwide Swedish multicenter study. Journal of Clinical Endocrinology and Metabolism 2016102 379-389. (doi:10.1210/jc.2016-2522)

19 Fichna M, Fichna P, Gryczyńska M, Walkowiak J, Żurawek M \& Sowiński J. Screening for associated autoimmune disorders in Polish patients with Addison's disease. Endocrine 201037 349-360. (doi:10.1007/s12020-010-9312-x)

20 Speiser PW, Azziz R, Baskin LS, Ghizzoni L, Hensle TW, Merke DP Meyer-Bahlburg HF, Miller WL, Montori VM, Oberfield SE, et al. Congenital adrenal hyperplasia due to steroid 21-hydroxylase deficiency: an Endocrine Society clinical practice guideline. Journal of Clinical Endocrinology and Metabolism 201095 4133-4160. (doi:10.1210/jc.2009-2631)

21 Betterle C, Scarpa R, Garelli S, Morlin L, Lazzarotto F, Presotto F, Coco G, Masiero S, Parolo A, Albergoni MP, et al. Addison's disease: a survey on 633 patients in Padova. European Journal of Endocrinology 2013169 773-784. (doi:10.1530/EJE-13-0528)

22 Husebye E, Allolio B, Arlt W, Badenhoop K, Bensing S, Betterle C, Falorni A, Gan EH, Hulting AL, Kasperlik-Zaluska A, et al. Consensus statement on the diagnosis, treatment and follow-up of patients with primary adrenal insufficiency. Journal of Internal Medicine 2014275 104-115. (doi:10.1111/joim.12162)

23 Smans LC, Van der Valk ES, Hermus AR \& Zelissen PM. Incidence of adrenal crisis in patients with adrenal insufficiency. Clinical Endocrinology 201684 17-22. (doi:10.1111/cen.12865)

24 Hahner S, Loeffler M, Bleicken B, Drechsler C, Milovanovic D, Fassnacht M, Ventz M, Quinkler M \& Allolio B. Epidemiology of adrenal crisis in chronic adrenal insufficiency: the need for new prevention strategies. European Journal of Endocrinology 2010162 597-602. (doi:10.1530/EJE-09-0884)

25 Erichsen MM, Løvås K, Fougner KJ, Svartberg J, Hauge ER, Bollerslev J, Berg JP, Mella B \& Husebye ES. Normal overall mortality rate in Addison's disease, but young patients are at risk of premature death. European Journal of Endocrinology 2009160 233-237. (doi:10.1530/EJE-08-0550)

26 Bergthorsdottir R, Leonsson-Zachrisson M, Odén A \& Johannsson G. Premature mortality in patients with Addison's disease: a populationbased study. Journal of Clinical Endocrinology and Metabolism 200691 4849-4853. (doi:10.1210/jc.2006-0076)

27 Rushworth RL \& Torpy DJ. A descriptive study of adrenal crises in adults with adrenal insufficiency: increased risk with age and in http://www.endocrineconnections.org DOI: 10.1530/EC-17-0295 (c) 2017 The authors Published by Bioscientifica Ltd

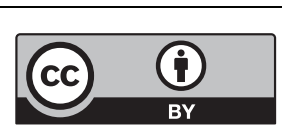

This work is licensed under a Creative Commons Attribution 4.0 International License. 
those with bacterial infections. BMC Endocrine Disorders 20141479. (doi:10.1186/1472-6823-14-79)

28 Løvås K, Loge JH \& Husebye ES. Subjective health status in Norwegian patients with Addison's disease. Clinical Endocrinology 200256 581-588. (doi:10.1046/j.1365-2265.2002.01466.x)

29 Hahner S, Loeffler M, Fassnacht M, Weismann D, Koschker A-C, Quinkler M, Decker O, Arlt W \& Allolio B. Impaired subjective health status in 256 patients with adrenal insufficiency on standard therapy based on cross-sectional analysis. Journal of Clinical
Endocrinology and Metabolism 200792 3912-3922. (doi:10.1210/ jc.2007-0685)

30 Crown A \& Lightman S. Why is the management of glucocorticoid deficiency still controversial: a review of the literature. Clinical Endocrinology 200563 483-492. (doi:10.1111/j.1365-2265.2005.02320.x)

31 Johannsson G, Falorni A, Skrtic S, Lennernäs H, Quinkler M, Monson JP \& Stewart PM. Adrenal insufficiency: review of clinical outcomes with current glucocorticoid replacement therapy. Clinical Endocrinology 201582 2-11. (doi:10.1111/cen.12603)

Received in final form 26 October 2017

Accepted 31 October 2017

Accepted Preprint published online 31 October 2017
(C) 2017 The authors Published by Bioscientifica Ltd

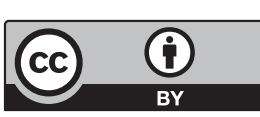

This work is licensed under a Creative Commons Attribution 4.0 International License. 